\title{
ASSESSING RELATIONS AMONG LANDSCAPE PREFERENCE, INFORMATIONAL VARIABLES, AND VISUAL ATTRIBUTES
}

\author{
Gaochao ZHANG ${ }^{1,2}$, Jun YANG ${ }^{1,2,3^{*}}$, Jing JIN $^{1}$ \\ ${ }^{1}$ Ministry of Education Key Laboratory for Earth System Modeling, Department of Earth System Science, \\ Tsinghua University, Beijing, China \\ ${ }^{2}$ Center for Healthy Cities, Institute for China Sustainable Urbanization, Tsinghua University, Beijing, China \\ ${ }^{3}$ Tsinghua Urban Institute, Beijing, China
}

Received 15 November 2020; accepted 21 May 2021

\author{
Highlights \\ There is an interaction effect of coherence and complexity on landscape preference. \\ - Relations among informational variables and visual attributes varied significantly. \\ Possible pathways to build landscape environments with both high coherence and complexity.
}

\begin{abstract}
The theory of preference matrix proposes coherence and complexity as informational variables to explain landscape preferences. To understand the relationship between the perceived coherence/complexity and the visual attributes of landscape scenes, we constructed multivariate generalized linear models based on a questionnaire study. A total of 488 respondents' ratings of the preference, the perceived coherence and complexity, and four visual attributes, namely, the openness of visual scale (openness), the richness of composing elements (richness), the orderliness of organization (orderliness), and the depth of view (depth), of a set of digitally manipulated landscape scenes were analyzed. The results showed that landscape preference needed to be explained with coherence and complexity together. Meanwhile, rather than showing the one-one connection with a single visual attribute, the degree of perceived coherence/complexity should be explained with multiple visual attributes. Ranked by explanatory power, the coherence was positively related to orderliness, negatively related to richness, and positively related to openness. The complexity was positively influenced by the level of richness, depth, and negatively influenced by orderliness and openness. Based on the results, feasible ways to build landscape environments with both preferable coherence and complexity were proposed.
\end{abstract}

Keywords: preference matrix, coherence, complexity, visual attributes, explanatory model, landscape management.

\section{Introduction}

A deeper understanding of landscape preference could help the practitioners to make environment diagnosis and predict if their design plans would be appreciated by the users after construction. The literature indicates that extensive factors influence the viewer's preference for landscape environments, e.g., the multi-sensory experiences (Deng et al., 2020), ecological values (Suppakittpaisarn et al., 2019), and geo-located individual-specific parameters (Foelske \& van Riper, 2020). At present, many landscape preference studies excessively concentrated on the fragmentary factors before a comprehensive picture of the general patterns about landscape visual preference was drawn. The fashion of landscape visual preference studies lied heavily on the comparisons of certain types of environments (e.g. urban built environments and nature environments) or certain elements, like water or plants in landscape environments (Chiang et al., 2017; Kotabe et al., 2017; Nasar \& Li, 2004; Nasar \& Lin, 2003; Valtchanov \& Ellard, 2015; Yang \& Brown, 1992). These findings showed that nature as a kind of environment was overall preferred by people compared to built environments. But how to make the landscape environments more appreciated by the potential users through design or management was less informed therein. In recent years more and more researchers realized this insufficiency and tried to explore people's preference for landscape environments based on visual or environmental features. Naturalness is the typical one which captures considerable attention from researchers (Beute \& de Kort,

${ }^{*}$ Corresponding author. E-mail: larix@tsinghua.edu.cn

Copyright $\odot 2021$ The Author(s). Published by Vilnius Gediminas Technical University

This is an Open Access article distributed under the terms of the Creative Commons Attribution License (http://creativecommons.org/licenses/by/4.0/), which permits unrestricted use, distribution, and reproduction in any medium, provided the original author and source are credited. 
2013; Hoyle et al., 2017; Ibarra et al., 2017; Marselle et al., 2015; Sowinska-Swierkosz \& Soszynski, 2019). At the same time, the complex relationships between the landscape preference and landscape attributes were explored with different methods such as conjoint analysis (Schirpke et al., 2019) and choice-modelling approach (Schüpbach et al., 2021). However, discrepancies widely existed in the available findings when explaining the relationships between landscape preference and different visual features of the landscape environment (Stamps, 2004).

From the theoretical view, it was widely accepted that people shared a common preference for landscape environments with certain visual features. The psychologists treated landscape visual preference as an outcome from the assessment about the usefulness of the environment based on the perceived information (Buss, 2015). The widely accepted theory explained landscape preference with the assumption that humans would prefer the landscape environments that could increase the chances of survival to gain evolutionary and adaptive benefits. The "prospectrefuge theory" pointed out that humans would subconsciously make assessments of the environments based on the visual properties (Appleton, 1996). Appleton claimed that human ancestors had the need to hunt and hide from the prey. So, humans were attracted to the environments with both the recognizable properties of "prospect" and "refuge". In the psycho-evolutionary framework, Ulrich (1983) summed up eight visual properties of landscape environments that influence the preference assessments. He believed that these visual properties were associated with better potentials for wellbeing. He suggested that humans got initial statements about the environments through the "affective state" before recognition. During this process, the gross structural aspects (complexity, organizational properties, focality), the gross depth properties (depth of spatiality, deflected vista), and the general class of compositional elements (the existence of threats, ground surface texture, and water) of the environments were assessed on the potential to human wellbeing.

The Kaplans generalized a matrix to explain landscape preference in their informational theory of visual preference (Kaplan et al., 1998). The preference matrix stated that people share cross-cultural consensuses on the preference for the nature environments that could satisfy their motivation to understand and explore. A good understanding of the environments would bring a sense of safety. An understandable environment had the properties to meet the desires of making sense of that environment and to help viewers to comprehend the surroundings to avoid getting into unsafe situations. Meanwhile, human ancestors needed to explore what lied ahead of the site to extend new habitats for living benefits. As a result, the environments that promised more information to come ahead would also be preferred. Based on these arguments, the preference matrix stated that the environment people preferred should have the properties to transmit information of coherence and legibility for understanding. At the same time, it needed to transmit complexity and mystery to meet the need for exploration. The coherence and complexity were based on the direct perception of the scenes as $2 \mathrm{D}$ images, which meant these two informational variables were immediately perceptible. While the legibility and mystery needed to be inferred from a 3D plane. They separately referred to if the varying levels of visual view and access could provide ease of orientation and more information for further exploration (Figure 1).

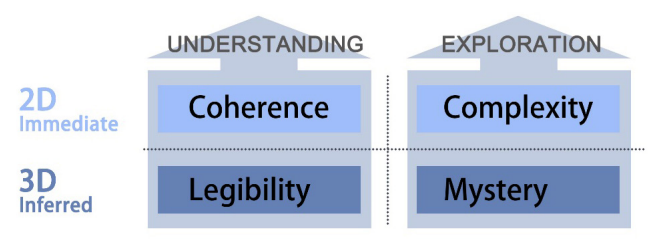

Figure 1. The preference matrix developed by Kaplan et al. (1998)

In long-lasting research traditions, this theory gained rootedness to explain research findings of landscape preference. But, different studies caught different sights of the relationships between the informational variables and landscape preference (Dronova, 2017). For example, researchers did not establish a uniform evidence base about the relationship between complexity and visual preference. Contrary to the statements that the complexity was a powerful variable to predict landscape visual preference (Kaplan et al., 1998), the studies by Coeterier (1996) and Sevenant and Antrop (2010) failed to establish a significant relationship between them. Similar problems also happened on the other informational variables, the metaanalysis by Stamps (2004) revealed that the explanatory power of a single informational variable did not show enough stability. The correlations between each informational variable and preference ranged from negative to considerably positive. These deficiencies were probably due to that the confounding factors related to different informational variables were not always comprehensively analyzed when probing the relations between a certain variable and preference. Another chief criticism about the preference matrix was its limited ability to apply the research results to actual landscape contexts (Stamps, 2004). Though the framework was frequently used for landscape preference explanation, its power for prediction was questionable (van der Jagt et al., 2014). Meanwhile, the present knowledge does not provide enough information to use the preference matrix to instruct design practice. The available findings on preference matrix do not yet give out systematic instructions about how to consciously alter the informational variables with the designer's approach, as the foundational knowledge that how the informational variables are determined by different visual attributes of the landscape is inadequate.

The preference matrix tried to explain the landscape preference by linking the landscape environments' visual characters with the cognitive assessment of them (Daniel, 2001). However, Kaplan et al. (1998) did not provide direct explanations about the relationship between the 
informational variables and different visual attributes. To be coherent, the whole environment should visually present a sense of unity. The organization of different elements through clear grouping was emphasized but how coherent an environment was perceived was also determined by the components and spatial features of that environment. By the same token, richness and diversity of elements might be the most important determinants of the perceived complexity, rather than the only one. Ode et al. (2010) pointed out that informational qualities like complexity did not have a one-to-one relationship with the visual features of the environment. Using one single attributional variable to represent an informational variable is easy to implement in studies, but might increase the possibility to get incomplete or unilateral conclusions. Before a proposed theory can be used to guide practice, the key concepts must be thoroughly investigated to be better understood by the potential users (Murphy, 2005). As a result, there are urgent needs to probe the associations between the attributes that have influences on preference and the informational qualities from the preference matrix (Ode et al., 2008, 2010). Yet such studies remained rare. More relevant evidence was needed to better establish the preference matrix as a framework for the landscape preference explanation, prediction, and design instruction.

This study aimed to provide better understanding of preference matrix by exploring the relationships between preference, the informational qualities of coherence and complexity, and visual attributes. The study was guided by the following research questions: (1) How do the informational variables of complexity-coherence interactively influence preference? (2) How are the perceived complexity and coherence determined by the visual attributes of the landscape? We conducted a questionnaire study to rate landscape and completed the preference appraisal, the evaluation of the informational variables, and the evaluations of different visual attributes.

\section{Methods}

\subsection{Variables selection}

The 3D informational variables "legibility" and "mystery" needed cognitive inference to be realized by the viewer. While the 2D informational variables "coherence" and "complexity" were realized immediately with the direct perception of the visual features of the environment (Figure 1). As a result, the informational variables "coherence" and "complexity" from the preference matrix were investigated in our study. The exact definitions of coherence and complexity differed slightly across studies (Foltête et al., 2020; Hunter \& Askarinejad, 2015; Kuper, 2017, 2020; Tveit et al., 2006). The definitions used in this study referred to the original statements by Kaplan and the previous studies on the preference matrix (van der Jagt et al., 2014). In the questionnaire, we described coherence as, how well the scene looked as a unity and the easiness to visually organize and structure the visual elements in the scene. The complexity referred to how intricate the scene is presented to the viewers as an integral image constituted by diverse elements and visual features.

The visual attributes investigated in this study were recognizable visual features about the landscape scenes that taking the whole environment as an integral. It was generally accepted that people do not perceive the whole as the sum of the parts, but a different one (Kubovy \& Cohen, 2001; Wolfe et al., 2008). As a result, it is reasonable to probe the universal discipline of landscape visual perception by focusing on a set of the attributional variables depicting different visual features of the integral environment. Each of the visual attributes included in this study was unidirectional. At the same time, they focused on different aspects of the environment to depict the general image of the scene together. These attributes were identified from theories and conceptual frameworks regarding landscape visual perception (Hunter \& Askarinejad, 2015; Tveit et al., 2006; Ulrich, 1983). We comprehensively assessed the related attributes based on the meaning, potential overlaps between attributes, and relations with our study design. At last, we included the openness of visual scale (openness), the richness of composing elements (richness), the orderliness of organization (orderliness), and the depth of view (depth) as the visual attributes for analysis. The explanations of the variables are listed in Table 1.

Table 1. Explanations of the variables

\begin{tabular}{|c|l|}
\hline Variable & \multicolumn{1}{|c|}{ Explanation } \\
\hline Coherence & $\begin{array}{l}\text { Coherence is the measure of the easiness to } \\
\text { organize and structure the scene when viewing } \\
\text { it as a unity (Hunter \& Askarinejad, 2015; } \\
\text { Kaplan et al., 1998; Stamps, 2004; Tveit et al., } \\
\text { 2006). }\end{array}$ \\
\hline Complexity & $\begin{array}{l}\text { Complexity refers to how intricate the scene is } \\
\text { presented to the viewers as an integral image } \\
\text { constituted by diverse elements and visual } \\
\text { features (Hunter \& Askarinejad, 2015; Kaplan } \\
\text { et al., 1998; Stamps, 2004; Tveit et al., 2006). }\end{array}$ \\
\hline Openness & $\begin{array}{l}\text { Openness refers to the perceived dimensional } \\
\text { spaciousness of the continuum of spaces visually } \\
\text { enclosed by the elementary composition of the } \\
\text { environment (Hunter \& Askarinejad, 2015; } \\
\text { Tveit et al., 2006). }\end{array}$ \\
\hline Richness & $\begin{array}{l}\text { Richness refers to the visually perceived level } \\
\text { of diversity of how the landscape environment } \\
\text { is composed of (Hunter \& Askarinejad, 2015; } \\
\text { Tveit et al., 2006). }\end{array}$ \\
\hline Depth & $\begin{array}{l}\text { Orderliness is the general evaluation of how } \\
\text { orderly the elements in the scene are visually } \\
\text { organized through patterns or linkages of } \\
\text { components (Hunter \& Askarinejad, 2015; } \\
\text { Tveit et al., 2006). }\end{array}$ \\
$\begin{array}{l}\text { Depth refers to the perceived proportional } \\
\text { relationships regarding the size of and distance } \\
\text { between the elements in different positions } \\
\text { (Hunter \& Askarinejad, 2015; Tveit et al., 2006). }\end{array}$ \\
\hline Orderliness
\end{tabular}




\subsection{The questionnaire}

The questionnaire was designed to rate a set of landscape pictures with different presentations on the selected visual attributes. This set of pictures were manipulated based on the same background image. Both the background and the manipulated pictures were presented in a realistic way to trigger the evaluation of the visual features close to real-world scenes (Daniel \& Meitner, 2001). The visual perception of the landscape environment picked the "fit together" of various landscape visual features. Factors that could possibly impact evaluations such as the color hues and brightness were controlled as much as possible by using the same background picture. To use scenes of vegetation only allowed for better focus on the variables of interest by avoiding the influences of other factors that can be easily raised by elements like buildings and environment types. The image manipulation was conducted with the software Photoshop (CC2016, Adobe). Through the different placements of the vegetations groups in front of the background, a set of scenes with different compositions or/and organizations were manipulated. To gather comments and suggestions to optimize the questionnaire, we conducted a pilot study in a group of ten researchers whose research focuses are in relevant fields. Based on their feedbacks, a set of six pictures were finally selected as they were considered to reach a balance between variable variation and the working burdens for respondents. Immoderate burdens on participants were found to increase the danger of irresponsible responses (Hunziker \& Kienast, 1999). The questionnaire was in Chinese. The exact expressions of the questions were optimized $t$ based on suggestions from the pilot study to promote the reliability of measurement and participants' comprehension. The operations on the selected scenes for rating were listed in Figure 2. The scenes on the same column had the same composition and different organizations, which were reflected in the way the plants were placed. The scenes on the same row were organized in the same way but the diversities of the composing elements were different.

Before the rating sections, we first collected the background information of the participants. The rating sections contained rating for the level of preference, two informational variables (coherence and complexity), and four visual attributional variables (openness, richness, orderliness, and depth) as discussed in the earlier part of the article, of each picture. In each section of the questionnaire, the respondents were asked to give a rating for one variable on each of the six scenes. The rating used 5-point scales where 1 stood for "not at all", 5 stood for "very much", and 2,3 and 4 for degrees in between. The ratings started with the training section where the respondents were asked to rate "how relaxed they would feel in the scenes". The training section used the same format as the
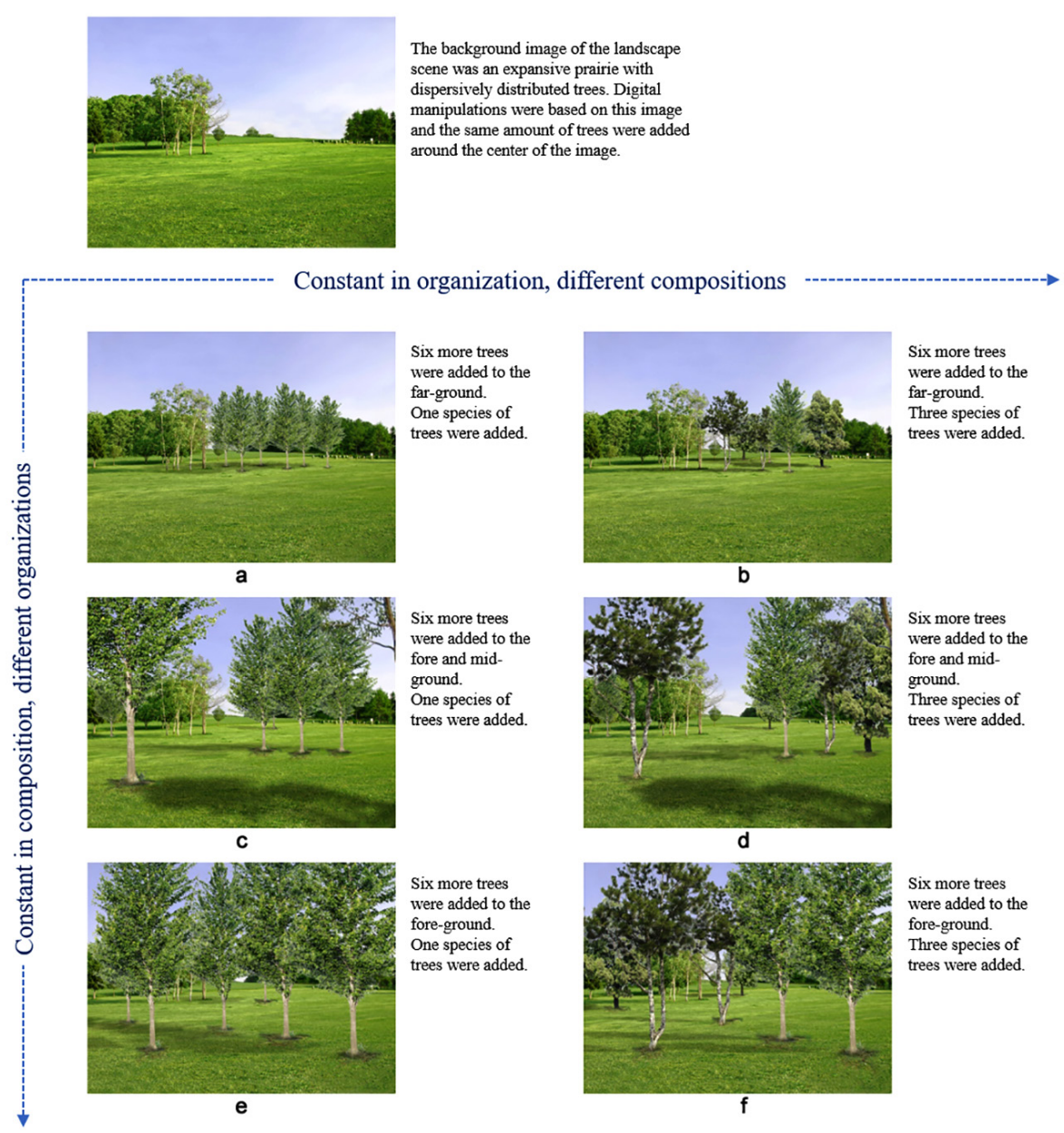

Figure 2. The landscape scenes used in the questionnaire 
formal rating section as it aimed to help the participants to get familiar with the questionnaire. The data of the training section would not be used for analysis. The section on "preference" asked the respondents to rate how much they like each scene. The rating sections for the informational variables and visual attributional variables started with a description of the meaning of the variable to be rated and then asked the respondents to give a score to each scene that agreed most to their direct visual perception about that variable (see complementary for details of the structure of the questionnaire).

\subsection{Data collection}

The questionnaire study was carried out through the online questionnaire platform Tencent Questionnaire. The questionnaire could be filled on devices like smart mobile phones, tablets, or computers. The questionnaire was first distributed after an online lecture about landscape and health whose audience were people with different backgrounds across the country. They were invited to fill this questionnaire after the lecture and encouraged to share this questionnaire to snowball the respondents. The questionnaire was also distributed on different social media by the authors.

The respondents were first given a brief description of the background of the investigation, as well as commitments of no misuse of the data. Participants could start to fill the questionnaire if they agreed with the statements. They were told that there were no judgments about right or wrong of the answers, and they should focus on the direct perception rather than repeating comparisons to give their ratings. The participants were first asked about their background information after which the rating sections follows. The questionnaire could be submitted only if all the sections were finished. The questionnaire collection started on 27 March 2020, and closed on 7 April 2020. The seasons for the rating was considered as a factor that could influence the preference rating for landscape (Kuper, 2020). Meanwhile, the outdoor scenes were changing rapidly at that season, and the policies to go out altered drastically based on the epidemic status of COVID-19. As a result, to control the influences from the above factors, the collecting period was not supposed to last long.

\subsection{Data analysis}

To analyze the relationships between the different variables, generalized linear model (GLM) regressions were performed. The analysis was based on $\mathrm{R}$ (version $\mathrm{x} 64$ 4.0.2). We first computed the variance inflation factor (VIF) to examine the multi-collinearity between visual attributes which were used as explanatory variables for the informational variables (coherence and complexity). The variables that passed the multi-collinearity test were retained for regression. Since the data type for the responses were not continuous variables but ordinal variables of integers, we fitted generalized linear models with Poisson regression with the R package of "glm". Three regressions were performed. First, the preference was put as the response variable and coherence and complexity as the explanatory variables to explore the relationship between preference and the two informational variables. Then we examined how the informational variables could be explained to a certain set of visual attributes by respectively using coherence and complexity as the response variable and the visual attributes as the explanatory variables. For each model, we included the variables that passed the significant test with $\mathrm{p}<0.001$. Based on this procedure, we constructed three models with the remaining variables.

\section{Results}

\subsection{Characteristics of the participants and questionnaire}

In total 670 respondents finished the questionnaire. The respondents showed a balance in gender composition and had diverse professional backgrounds (see Figure 3).

Age was found to be a factor to influence landscape preference evaluation (Sevenant \& Antrop, 2010; Tempesta, 2010). Compared to adults, juveniles do not yet develop stable aesthetic sensibilities (Kalivoda et al., 2014). At the same time, the proportion of respondents older than 40 years old is quite small, i.e., $1.9 \%$. As a result, we excluded the questionnaires from respondents aged beyond 40 and below 18 to reduce the impacts from the factor of age. The responses that gave the same rating for the different scenes in any individual section would be taken out from the data pool as it indicated unqualified participation. The data from 488 respondents were used for the eventual analysis. More than $99 \%$ of the respondents used their mobile phones to fill out this questionnaire. The questionnaire showed a Cronbach's $\alpha$ of 0.88 , which meant this questionnaire had a high quality of reliability. Across variables, the consistency of evaluation varied. The coherence had a Cronbach's $\alpha$ of 0.73 , the complexity was

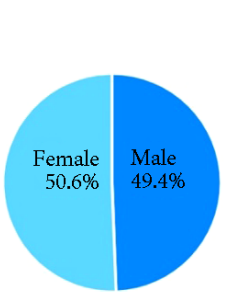

a) Gender composition

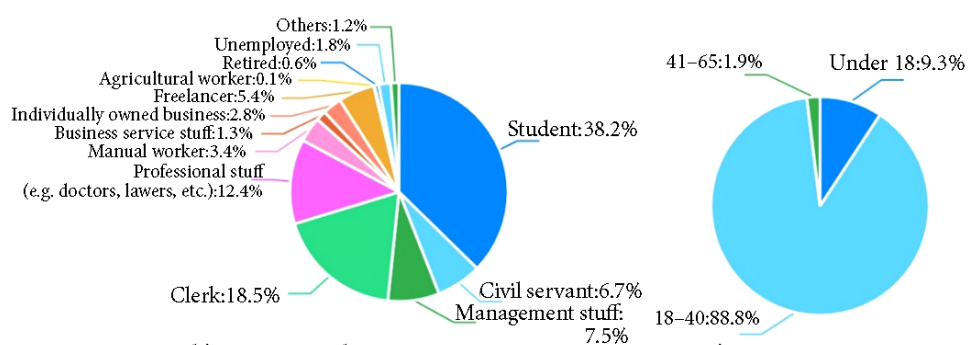

b) Ocupational composition c) Age composition

Figure 3. The socio-demographic profile of respondents 
0.65. While for the visual attributes, the Cronbach's a was: openness (0.73), richness (0.79), order (0.65), and depth (0.69).

\subsection{Ratings of the scenes}

The means for the rated variables for each scene were shown in Table 2.

The distribution of rating for preference, coherence and complexity could be seen from Figure 4 .

We tested for the significant interactions between the visual attributional variables. The VIFs for all the visual attributes (Appendix) show that the collinearity concerns were not proved to be important. As a result, the four visual attributes (openness, richness, orderliness, and depth) could all be included for the GLM regression.

\subsection{The model of the relationship between landscape preference and coherence - complexity}

The outputs of the Poisson GLM for preference and the two informational variables were listed in Table 3. Both the perceived coherence and complexity showed significant influences on landscape preference. The influence on preference by both coherence and complexity were positive, with coherence showing stronger coefficient value.

As a result, the model of "preference $\sim$ coherence + complexity" could be expressed as:

$$
\begin{aligned}
& \text { preference }_{i} \sim \text { poisson }\left(\mu_{i}\right) \\
& E\left(\text { preference }_{i}\right)=\operatorname{var}\left(\text { preference }_{i}\right)=\mu_{i} \\
& \log \left(\mu_{i}\right)=\eta_{i} ; \\
& \eta_{i}=0.60+0.15 \times \text { coherence }_{i}+0.03 \times \text { complexity }_{i} .
\end{aligned}
$$

Table 3. The output of the final GLM models for "preference coherence + complexity"

\begin{tabular}{|l|c|c|c|c|}
\hline $\begin{array}{c}\text { Predictor } \\
\text { variable }\end{array}$ & Estimate & Std. Error & Z Value & $\operatorname{Pr}(>|z|)$ \\
\hline Intercept & 0.60 & 0.05 & 11.42 & $<0.001^{* * *}$ \\
\hline Coherence & 0.15 & 0.01 & 14.89 & $<0.001^{* * *}$ \\
\hline Complexity & 0.03 & 0.01 & 3.43 & $<0.001^{* * *}$ \\
\hline
\end{tabular}

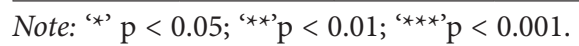

\subsection{The models of the relationship between coherence/complexity and the different visual attributes}

In these regressions, the openness, richness, order, and depth were first used as independent variables together. The coherence and complexity were respectively used as dependent variables. When the four visual attributes were all put as independent variables to explain the coherence, the depth did not pass the significance test (see Appendix).

After removing the depth from the independent variables, all the coefficients passed the significance test at the level of $p<0.001$. The outputs of the Poisson GLM for coherence and the three visual attributes were fitted as below (Table 4). Openness and orderliness have positive influence on the level of coherence, while richness influences the coherence from the opposite direction. Among the three variables, orderliness has the largest coefficient in the model.

The model "coherence $\sim$ openness + richness + orderliness" is thus expressed as:

$$
\begin{aligned}
& \text { coherence }_{i} \sim \text { poisson }\left(\mu_{i}\right) ; \\
& E\left(\text { coherence }_{i}\right)=\operatorname{var}\left(\text { coherence }_{i}\right)=\mu_{i} ;
\end{aligned}
$$

Table 2. Means of rating for preference and the variables for the scenes

\begin{tabular}{|c|c|c|c|c|c|c|c|}
\hline Scenes & Preference & Coherence & Complexity & Openness & Richness & Order & Depth \\
\hline a & $3.97(0.83)$ & $4.01(0.73)$ & $2.62(0.89)$ & $4.49(0.60)$ & $2.91(0.77)$ & $3.95(0.81)$ & $2.77(0.85)$ \\
\hline b & $3.77(0.95)$ & $3.29(0.89)$ & $3.39(0.95)$ & $4.40(0.62)$ & $4.14(0.69)$ & $3.47(0.84)$ & $3.27(0.85)$ \\
\hline c & $3.97(0.79)$ & $3.64(0.74)$ & $3.12(0.85)$ & $3.36(0.68)$ & $3.09(0.72)$ & $3.68(0.82)$ & $4.09(0.69)$ \\
\hline d & $2.84(0.90)$ & $2.17(0.87)$ & $3.98(0.94)$ & $3.34(0.67)$ & $4.25(0.68)$ & $2.24(0.86)$ & $3.91(0.74)$ \\
\hline e & $2.57(0.80)$ & $3.77(0.82)$ & $2.36(0.99)$ & $2.00(0.73)$ & $1.97(0.74)$ & $3.16(0.96)$ & $2.07(0.81)$ \\
\hline f & $2.61(0.93)$ & $2.26(0.82)$ & $3.61(0.92)$ & $1.93(0.73)$ & $3.27(0.87)$ & $2.65(0.83)$ & $2.54(0.77)$ \\
\hline
\end{tabular}
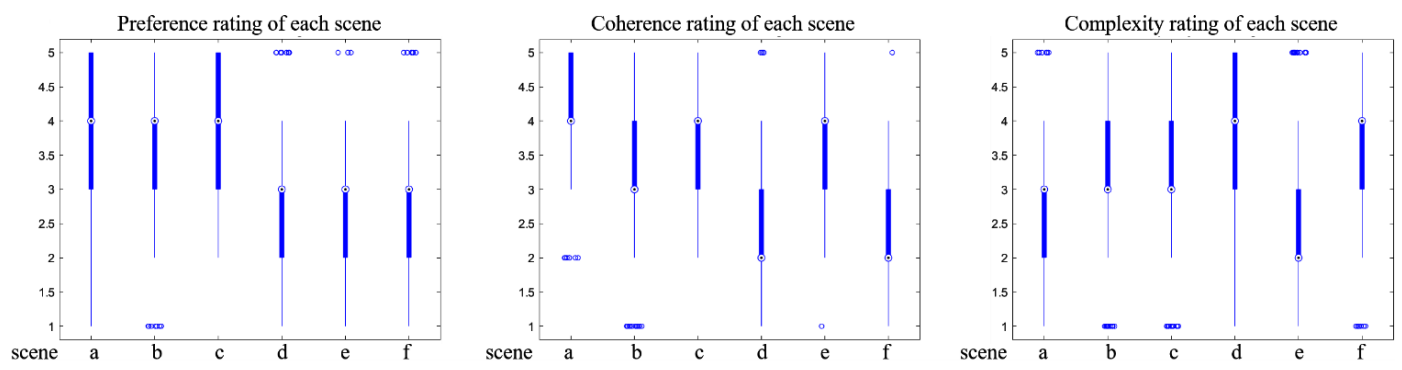

Figure 4. The box-plots for the ratings of the preference, coherence and complexity 
Table 4. The output of the final GLM models for "coherence openness + richness + orderliness"

\begin{tabular}{|l|c|c|c|c|}
\hline $\begin{array}{c}\text { Predictor } \\
\text { variable }\end{array}$ & Estimate & Std. Error & Z Value & $\operatorname{Pr}(>|z|)$ \\
\hline Intercept & 0.80 & 0.05 & 16.42 & $<0.001^{\star * *}$ \\
\hline openness & 0.07 & 0.01 & 6.89 & $<0.001^{\star * *}$ \\
\hline richness & -0.09 & 0.01 & -8.86 & $<0.001^{\star * *}$ \\
\hline orderliness & 0.13 & 0.01 & 11.90 & $<0.001^{\star * *}$ \\
\hline
\end{tabular}

Note: '*' $\mathrm{p}<0.05$; ‘*’ $\mathrm{p}<0.01$; “***' $\mathrm{p}<0.001$.

$$
\begin{aligned}
& \log \left(\mu_{i}\right)=\eta_{i} \\
& \eta_{i}=0.80+0.07 \times \text { openness }_{i}- \\
& 0.09 \times \text { richness }_{i}+0.13 \times \text { orderliness }_{i} .
\end{aligned}
$$

When using complexity as the dependent variable, all the four visual attributes passed the significance test $(\mathrm{p}<0.001)$ in the model. The outputs of the Poisson GLM for complexity and the four visual attributes were listed in Table 5. Richness had larger influence than other visual attributes. The influence from richness and depth on complexity were positive, while the influence from openness and orderliness were negative.

Table 5. The output of the final GLM models for "complexity openness + richness + orderliness + depth"

\begin{tabular}{|l|c|c|c|c|}
\hline $\begin{array}{c}\text { Predictor } \\
\text { variable }\end{array}$ & Estimate & Std. Error & Z Value & $\operatorname{Pr}(>|\mathrm{z}|)$ \\
\hline Intercept & 0.80 & 0.05 & 15.82 & $<0.001^{\star * *}$ \\
\hline openness & -0.03 & 0.01 & -3.01 & $0.003^{\star *}$ \\
\hline richness & 0.13 & 0.01 & 11.38 & $<0.001^{\star * *}$ \\
\hline orderliness & -0.05 & 0.01 & -4.22 & $<0.001^{* * *}$ \\
\hline depth & 0.05 & 0.01 & 4.17 & $<0.001^{* * *}$ \\
\hline
\end{tabular}

Note: '*' $\mathrm{p}<0.05$; ‘*’ $\mathrm{p}<0.01$; $^{(* * *)} \mathrm{p}<0.001$.

The model of "complexity $\sim$ openness + richness + orderliness + depth" is expressed as:

$$
\begin{aligned}
& \text { complexity }_{i} \sim \text { poisson }\left(\mu_{i}\right) \\
& E\left(\text { complexity }_{i}\right)=\operatorname{var}\left(\text { complexity }_{i}\right)=\mu_{i} ; \\
& \log \left(\mu_{i}\right)=\eta_{i} ; \\
& \eta_{i}=0.80-0.03 \times \text { openness }_{i}+0.13 \times \text { richness }_{i}+ \\
& 0.05 \times \text { depth }_{i}-0.05 \times \text { orderliness }_{i} .
\end{aligned}
$$

\section{Discussion}

\subsection{The interactive influence of coherence and complexity on landscape preference}

The result shows that both the informational variables of coherence and complexity could significantly and positively influence viewers' landscape visual preference together. In this model, the values of the variables for the models range from 1 of bottom-end to 5 top-end. According to the model, when either of the two informational variables stays very low, even if the other informational variable could reach high values, the landscape scene could hardly get high preference value. This directly indicates that neither informational variable (coherence or complexity) should be individually used as a powerful predictor for people's preference for certain landscape environments. In fact, this was directly supported by the preference rating of the scenes. Among the 6 landscape scenes in our investigation, scene "d" showed high complexity while low coherence, scene "e" showed high coherence but low complexity, both had low preference ratings among the six scenes. Based on the interactive influence of coherence and complexity on landscape preference evaluation revealed by the model, we can infer that the environments that people prefer should transmit balanced and high degree of coherence and complexity on visual perception, as people are thought to prefer the environments with enough to explore while not too difficult to understand (Kaplan et al., 1998).

The perceived coherence and complexity together provide powerful explanations for landscape preference, but the role for each individual informational variable differs. The weight of coherence in the model is much stronger than complexity, which means that high visually coherent perception of an environment is fundamental to high visual preference. The complexity could be a stronger predictor of preference when the visual coherence of the scene is not disrupted. In previous work, the Kaplan and Kaplan (1989) distinguished complexity into two types: complexity with order and complexity without order. The former provided visual richness while the latter would probably lead to perceived chaos. The results stand with Kaplan's early statements that without sacrifice coherence, high complexity could contribute to preference (Kaplan \& Kaplan, 1989). The interacting pattern also corresponds to the research findings that scenes with fractal geometry - a complex structure that remained coherent - would get a stable preference evaluation as indicated from perceptual and physiological responses (Taylor et al., 2011). The previous studies probed the relationships between complexity and preference reached different statements. Some of the studies proved that complexity was positively related to landscape preference (Kuper, 2017). While there were also studies showing invert "U" shaped relations, which meant that moderate levels of complexity were more preferred (Ulrich, 1983). Ulrich explained this divergence as that the findings with unidirectional relation could probably reflect only one side of the inverted $U$ relationship. Based on the result, we would give another explanation to reply to these concerns. It was possible that the level of coherence across landscape scenes for evaluation was not strictly controlled in some cases. Providing that the complexity of the scenes used for evaluation increased while being less coherent, the evaluation of preference would be improbably to increase. It was a common practice to investigate the relationship between preference and one 
informational variable (coherence or complexity) in isolation (van der Jagt et al., 2014). Here our findings showed the necessity to explore the interactive influence pattern of these two variables. Van der Jagt et al. (2014) explored their interactive patterns by showing the relationship between the estimated beauty and the complexity when the coherence was either high or low. It was found that when the coherence was very high, the hedonic value showed a tendency of firstly rose then slightly dropped with the increase of complexity. When the coherence was low and mediate, the hedonic value rose with the complexity value. It needs to point out that, that study did not show a dynamic interaction of these two variables but set a bound on the coherence value to show the different relationships between complexity and preference on each side. However, the coherence was not pledged to remain stable on either side. As a result, our findings should not be considered as conflicting with the results of van der Jagt et al. (2014). Instead, our findings corresponded with the statement from van der Jagt et al. (2014) that the complexity contributed more positively to the hedonic evaluation for landscape when the coherence was high.

In summary, the explaining power of the preference matrix would be better realized if the relationships between preference and the informational variables were explored from an interactive perspective. In landscape design and management, it needs to avoid the piecewise augment in one informational quality whereas neglecting the other. It is widely considered that the augment of complexity would increase the challenges to maintain high coherence. But our findings suggest that coherence should not be simply considered as an opposite side of complexity. This supports the statement that a landscape setting showing a high level of coherence could simultaneously present a high level of complexity (Kaplan \& Kaplan, 1989). But both coherence and complexity are variables related to the perceived information from the environments, rather than attributes about the physical environment itself. Better linkage between the landscape visual attributes and the theoretical concepts would provide chances for practitioners to predict the advantages and disadvantages of their proposed design actions.

\subsection{The relationships between coherence, complexity, and visual attributes}

The Cronbach's Alphas for different variables indicated that there were fundamental agreements for what the concepts referred to on landscape visual perception, even though the participants hold more discrepant understandings or criteria of assessment for the complexity, order, and depth than the other three. At the same time, the four visual attributes showed a low level of collinearity which partly indicated that they reflected the different visual features of landscape environments and could corporately be used to portray the general visual perception of landscape environments.

The modeling result reveals the relations between coherence and complexity and the four visual attributes.
The informational variable of coherence was mainly associated with the level of the orderliness of the organization, openness in spatiality, and negatively related to the richness of the composing elements of the environment. Complexity was positively related to the richness of the composing elements and depth of view, and negatively related to the openness of visual scale and orderliness of organization. For either of the informational variable, no one-to-one correspondences with any single visual attribute were detected. This result should raise the attention on using single visual attribute to represent an informational variable (e.g. use the diversity of elements to present complexity), which were widely adopted in previous study designs (Ode et al., 2010). Here we can see that both coherence and complexity were closely related to different compositional and organizational features. The complexity is most related to the richness of elements composing the environment, while the coherence is largely affected by the orderliness of how the elements are organized. For the other related visual attributes, the openness and depth respectively reflect the continuity and hierarchy of the space and elements. Greater depth of view could provide richer experiential possibilities and cues for exploration (Hunter \& Askarinejad, 2015; Ulrich, 1983). This feature supplemented the perceived complexity from the environments by transferring information of chances for exploration to the viewers, but it provided no significant explanation for coherence. Openness had a positive influence on coherence and a negative influence on complexity. This could be explained as that openness assured visibility, environments with greater openness could be more understandable, while would reduce the chances for exploration. But the small weights indicated that openness was not a strong determinant for both coherence and complexity. The results of this study provided important information to make a more comprehensive linkage between the informational variables and different visual attributes which would help to make evidence-based strategies to realize the scenario of landscape environments with high complexity and coherence together.

In the explanatory models, coherence and complexity shared three common visual attributes as predicting variables. The common variables provided inverse and different-weighted influences on coherence and complexity. At the same time, the depth of view only showed a significant influence on the complexity and the explanatory power was strong (higher than order and openness). This confirmed that coherence and complexity cannot be regarded as the opposite directions of the same features of the environments. Ulrich (1983) pointed out that it was common that the theories about landscape only provided general statements without clear definitions of the key concepts. He referred to this fact as the main shortage for preference prediction on a theoretical base. As for the preference matrix, the previous research findings did not yet provide enough conclusive evidence to consummate the theoretical foundation (van der Jagt et al., 2014). 
These deficiencies signified that the key concepts of the preference matrix should make better elucidations of the relations between the informational variables and the attributes related to the visual perception of landscape environments. The findings here provide some insights: it is not proper to use any single visual attribute as a substitution for the informational variable; rather, coherence and complexity should be understood as qualities of the integral environment based on the visually perceived information from the combination of the distribution of landscape elements, spatial organization and the disparities of the apparent features of elements.

At last, our results point to some possible pathways to help the practitioners to make environments with both a good level of coherence and complexity in reality. The openness would be suggested to categorize the environment units as openness shows the significant but limited influence on coherence and complexity. Design interventions could consciously alter other visual attributional qualities of the environments with different degrees of openness to shape the aimed combination of coherence and complexity. To maintain complexity without harming the coherence, the diverse elements could be organized into clear and hierarchical patterns for a better sense of order. Meanwhile, the perceived complexity could be further promoted by organizing the space with richer proportional relationships to build a better depth of view. It needs to avoid the over-promotion of certain visual attributes without rational management of others as some visual attributes had opposite power on the determination of the coherence and complexity. For example, the augment of the richness of plant species without clear spatial planning may lead to a significant decrease of preference as this action would cause a serious reduction in coherence than the improvement of complexity. There is long-lasting criticism for landscape architects' lack of knowledge base to refer to when proposing landscape changes (Murphy, 2005). This concern could be responded to with powerful theoretical frameworks that could instruct the practitioners to make decisions with predictable assessments of the advantages or disadvantages of a proposed course of action (Murphy, 2005). From this perspective, more studies should be carried out to make better identification of the relationships between the concepts from the preference matrix and the attributional qualities that could be consciously altered with the designer's approaches.

\subsection{Limitations}

In this study, we selected four visual attributes as variables to capture basic images of the landscape visual perception. Possibilities of overlooking some other drivers about landscape visual preference exist. This study used artificially created scenes primarily composed of lawns and trees which allowed us to control confounding factors. In scenes that are more discordant, more complex interpretations might be needed. However, the visual attributes were reported to be more fundamental for landscape preferences than landscape types. Kalivoda et al. (2014) found that the differences in the preferences for different landscape types were not significant after controlling the factors of visual aesthetic quality. Nevertheless, the coupling between visual attributes and factors such as culture deserves more evaluation. Young and old people were found to assess scenes with remarkable differences, and the landscape preference of people aged in between tended to be more homogenous (Kalivoda et al., 2014). Because of the small proportion of the respondents older than 40, we didn't include this group of adults for analysis. A more balanced representation of different age groups may be desirable. Here, limited by the application of 2D pictures, we could not explore the informational variables of legibility and mystery from the preference matrix. Future studies could make further explorations about them with the use of media like virtual reality.

\section{Conclusions}

This study attempted to bridge the theory of preference matrix with the visual attributes that influence the visual perception of landscape environments. Based on the data from a questionnaire study, we constructed three log-linear regression models to explain: (1) the interactive influence of coherence and complexity on landscape preference and (2) the relationship between the perceived coherence/ complexity and four visual attributes (openness, richness, orderliness, and depth). The results showed that the landscape preference should be explained with the perceived coherence and complexity together rather than either individual one. When keeping the environments to be coherent, the increasing complexity would promote people's preferential evaluation. The perceived coherence and complexity of the environments were both influenced by the openness of spatiality, the orderliness of organization, and the richness of the composing elements of the landscape environments. These three visual attributes showed different degrees of explanatory power with opposite directions on the explanation of the two informational variables. The complexity had an additional explanatory variable than coherence, namely depth of view. Our findings could provide guidance for the landscape practitioners to make environments that people prefer. For instance, with the patterns revealed from the models, the landscape architects could orderly group and organize the diverse elements and improve the depth of view to make a landscape environment with both preferable coherence and complexity. More studies were needed to probe how to achieve the ideal combination of coherence and complexity with landscape design approaches to strengthen the potential to guide practice with preference matrix.

\section{References}

Appleton, J. (1996). The experience of landscape. Wiley.

Beute, F., \& de Kort, Y. A. (2013). Let the sun shine! Measuring explicit and implicit preference for environments differing in 
naturalness, weather type and brightness. Journal of Environmental Psychology, 36, 162-178.

https://doi.org/10.1016/j.jenvp.2013.07.016

Buss, D. (2015). Evolutionary psychology: The new science of the mind ( $5^{\text {th }}$ ed.). Psychology Press.

https://doi.org/10.4324/9781315663319

Chiang, Y.-C., Li, D., \& Jane, H.-A. (2017). Wild or tended nature? The effects of landscape location and vegetation density on physiological and psychological responses. Landscape and Urban Planning, 167, 72-83.

https://doi.org/10.1016/j.landurbplan.2017.06.001

Coeterier, J. (1996). Dominant attributes in the perception and evaluation of the Dutch landscape. Landscape and Urban Planning, 34(1), 27-44.

https://doi.org/10.1016/0169-2046(95)00204-9

Daniel, T. C. (2001). Whither scenic beauty? Visual landscape quality assessment in the 21st century. Landscape and Urban Planning, 54(1-4), 267-281.

https://doi.org/10.1016/S0169-2046(01)00141-4

Daniel, T. C., \& Meitner, M. M. (2001). Representational validity of landscape visualizations: the effects of graphical realism on perceived scenic beauty of forest vistas. Journal of Environmental Psychology, 21(1), 61-72.

https://doi.org/10.1006/jevp.2000.0182

Deng, L., Luo, H., Ma, J., Huang, Z., Sun, L.-X., Jiang, M.-Y., Zhu, C.-Y., \& Li, X. (2020). Effects of integration between visual stimuli and auditory stimuli on restorative potential and aesthetic preference in urban green spaces. Urban Forestry \& Urban Greening, 53, 126702. https://doi.org/10.1016/j.ufug.2020.126702

Dronova, I. (2017). Environmental heterogeneity as a bridge between ecosystem service and visual quality objectives in management, planning and design. Landscape and Urban Planning, 163, 90-106.

https://doi.org/10.1016/j.landurbplan.2017.03.005

Foelske, L., \& van Riper, C. J. (2020). Assessing spatial preference heterogeneity in a mixed-use landscape. Applied Geography, 125. https://doi.org/10.1016/j.apgeog.2020.102355

Foltête, J.-C., Ingensand, J., \& Blanc, N. (2020). Coupling crowd-sourced imagery and visibility modelling to identify landscape preferences at the panorama level. Landscape and Urban Planning, 197, 103756.

https://doi.org/10.1016/j.landurbplan.2020.103756

Hoyle, H., Hitchmough, J., \& Jorgensen, A. (2017). All about the 'wow factor'? The relationships between aesthetics, restorative effect and perceived biodiversity in designed urban planting. Landscape and Urban Planning, 164, 109-123. https://doi.org/10.1016/j.landurbplan.2017.03.011

Hunter, M. R., \& Askarinejad, A. (2015). Designer's approach for scene selection in tests of preference and restoration along a continuum of natural to manmade environments. Frontiers in Psychology, 6, 1228. https://doi.org/10.3389/fpsyg.2015.01228

Hunziker, M., \& Kienast, F. (1999). Potential impacts of changing agricultural activities on scenic beauty - a prototypical technique for automated rapid assessment. Landscape Ecology, 14(2), 161-176. https:/doi.org/10.1023/A:1008079715913

Ibarra, F. F., Kardan, O., Hunter, M. R., Kotabe, H. P., Meyer, F. A., \& Berman, M. G. (2017). Image feature types and their predictions of aesthetic preference and naturalness. Frontiers in Psychology, 8, 632. https://doi.org/10.3389/fpsyg.2017.00632

Kalivoda, O., Vojar, J., Skrivanova, Z., \& Zahradnik, D. (2014). Consensus in landscape preference judgments: the effects of landscape visual aesthetic quality and respondents' characteristics. Journal of Environmental Management, 137, 36-44. https://doi.org/10.1016/j.jenvman.2014.02.009
Kaplan, R., \& Kaplan, S. (1989). The experience of nature: A psychological perspective. Cambridge University Press. https://psycnet.apa.org/record/1989-98477-000

Kaplan, R., Kaplan, S., \& Ryan, R. (1998). With people in mind: Design and management of everyday nature. Island Press. https://books.google.lt/books/about/With_People_in_Mind. html?id=snqtOUwqlXsC\&redir_esc $=y$

Kotabe, H. P., Kardan, O., \& Berman, M. G. (2017). The naturedisorder paradox: A perceptual study on how nature is disorderly yet aesthetically preferred. Journal of Experimental Psychology: General, 146(8), 1126-1142.

https://doi.org/10.1037/xge0000321

Kubovy, M., \& Cohen, D. J. (2001). What boundaries tell us about binding. Trends in Cognitive Sciences, 5(3), 93-95. https://doi.org/10.1016/S1364-6613(00)01604-1

Kuper, R. (2017). Evaluations of landscape preference, complexity, and coherence for designed digital landscape models. Landscape and Urban Planning, 157, 407-421. https://doi.org/10.1016/j.landurbplan.2016.09.002

Kuper, R. (2020). Preference and restorative potential for landscape models that depict diverse arrangements of defoliated, foliated, and evergreen plants. Urban Forestry \& Urban Greening, 48, 126570. https://doi.org/10.1016/j.ufug.2019.126570

Marselle, M. R., Irvine, K. N., Lorenzo-Arribas, A., \& Warber, S. L. (2015). Moving beyond green: exploring the relationship of environment type and indicators of perceived environmental quality on emotional well-being following group walks. International Journal of Environmental Research and Public Health, 12(1), 106-130. https://doi.org/10.3390/ijerph120100106

Murphy, M. (2005). Landscape architecture theory. Island Press. https://doi.org/10.5822/978-1-61091-751-3

Nasar, J., \& Li, M. (2004). Landscape mirror: the attractiveness of reflecting water. Landscape and Urban Planning, 66(4), 233-238. https://doi.org/10.1016/S0169-2046(03)00113-0

Nasar, J., \& Lin, Y.-H. (2003). Evaluative responses to five kinds of water features. Landscape Research, 28(4), 441-450. https://doi.org/10.1080/0142639032000150167

Ode, Å., Hagerhall, C. M., \& Sang, N. (2010). Analysing visual landscape complexity: theory and application. Landscape Research, 35(1), 111-131. https://doi.org/10.1080/01426390903414935

Ode, Å., Tveit, M. S., \& Fry, G. (2008). Capturing landscape visual character using indicators: touching base with landscape aesthetic theory. Landscape Research, 33(1), 89-117. https://doi.org/10.1080/01426390701773854

Schirpke, U., Tappeiner, G., Tasser, E., \& Tappeiner, U. (2019). Using conjoint analysis to gain deeper insights into aesthetic landscape preferences. Ecological Indicators, 96, 202-212. https://doi.org/10.1016/j.ecolind.2018.09.001

Schüpbach, B., Weiß, S. B., Jeanneret, P., Zalai, M., Szalai, M., \& Frör, O. (2021). What determines preferences for seminatural habitats in agrarian landscapes? A choice-modelling approach across two countries using attributes characterising vegetation. Landscape and Urban Planning, 206, 103954. https://doi.org/10.1016/j.landurbplan.2020.103954

Sevenant, M., \& Antrop, M. (2010). The use of latent classes to identify individual differences in the importance of landscape dimensions for aesthetic preference. Land Use Policy, 27(3), 827-842. https://doi.org/10.1016/j.landusepol.2009.11.002

Sowinska-Swierkosz, B., \& Soszynski, D. (2019). The index of the Prognosis Rural Landscape Preferences (IPRLP) as a tool of generalizing peoples' preferences on rural landscape. Journal of Environmental Management, 248, 109272. https://doi.org/10.1016/j.jenvman.2019.109272 
Stamps, A. (2004). Mystery, complexity, legibility and coherence: A meta-analysis. Journal of Environmental Psychology, 24(1), 1-16. https://doi.org/10.1016/S0272-4944(03)00023-9

Suppakittpaisarn, P., Larsen, L., \& Sullivan, W. C. (2019). Preferences for green infrastructure and green stormwater infrastructure in urban landscapes: Differences between designers and laypeople. Urban Forestry \& Urban Greening, 43, 126378. https://doi.org/10.1016/j.ufug.2019.126378

Taylor, R., Spehar, B., Hagerhall, C., \& Van Donkelaar, P. (2011). Perceptual and physiological responses to Jackson Pollock's fractals. Frontiers in Human Neuroscience, 5, 60. https://doi.org/10.3389/fnhum.2011.00060

Tempesta, T. (2010). The perception of agrarian historical landscapes: A study of the Veneto plain in Italy. Landscape and Urban Planning, 97(4), 258-272.

https://doi.org/10.1016/j.landurbplan.2010.06.010

Tveit, M., Ode, Å., \& Fry, G. (2006). Key concepts in a framework for analysing visual landscape character. Landscape Research, 31(3), 229-255. https://doi.org/10.1080/01426390600783269

Ulrich, R. S. (1983). Aesthetic and affective response to natural environment. In Human Behavior and Environment: Vol. 6.
Behavior and the natural environment (pp. 85-125). Springer. https://doi.org/10.1007/978-1-4613-3539-9_4

Valtchanov, D., \& Ellard, C. G. (2015). Cognitive and affective responses to natural scenes: effects of low level visual properties on preference, cognitive load and eye-movements. Journal of Environmental Psychology, 43, 184-195.

https://doi.org/10.1016/j.jenvp.2015.07.001

van der Jagt, A. P. N., Craig, T., Anable, J., Brewer, M. J., \& Pearson, D. G. (2014). Unearthing the picturesque: The validity of the preference matrix as a measure of landscape aesthetics. Landscape and Urban Planning, 124, 1-13. https://doi.org/10.1016/j.landurbplan.2013.12.006

Wolfe, J. M., Kluender, K. R., Levi, D. M., Bartoshuk, L. M., Herz, R. S., Klatzky, R. L., Lederman, S. J., \& Merfeld, D. (2008). Sensation \& perception ( $2^{\text {nd }}$ ed.). Sinauer Associates.

Yang, B.-E., \& Brown, T. J. (1992). A cross-cultural comparison of preferences for landscape styles and landscape elements. Environment and Behavior, 24(4), 471-507. https://doi.org/10.1177/0013916592244003

\section{APPENDIX}

1. The structure of the questionnaire

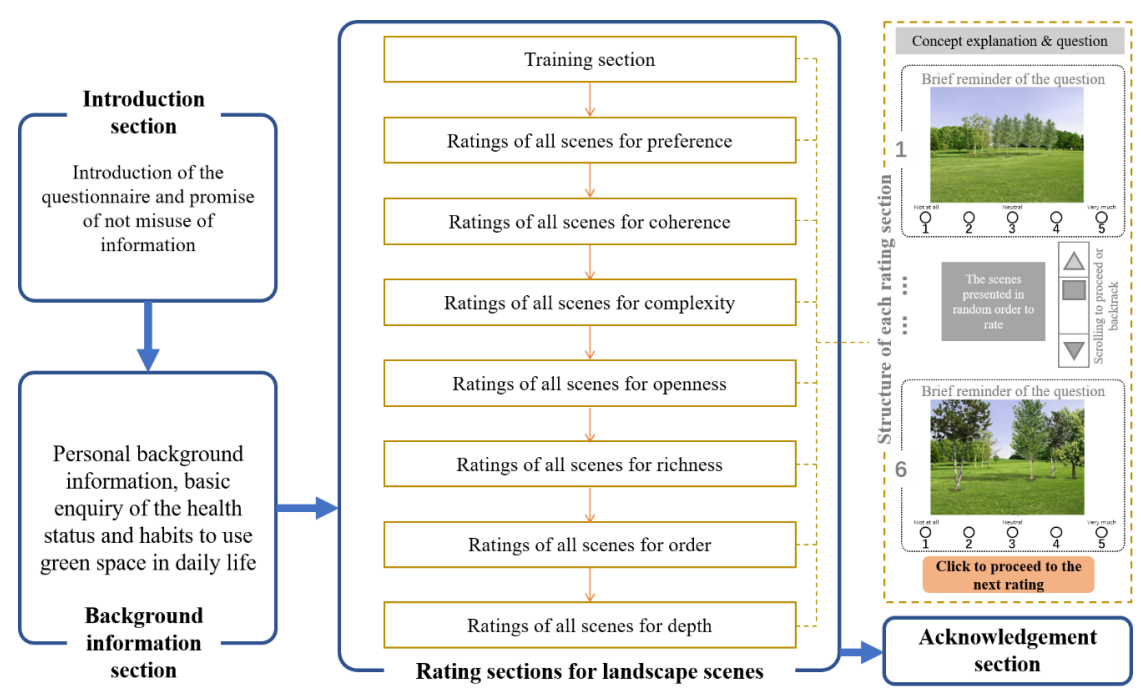

2. VIF for the four visual attributes

openness 1.390115; richness 1.449762; orderliness 1.207807; depth 1.355025.

3. The outputs of the model when using all the visual attributes as independent variables and coherence as dependent variable.

\begin{tabular}{|c|c|c|c|c|c|}
\hline & Estimate & Std. Error & $\mathrm{z}$ value & $\operatorname{Pr}(>|z|)$ & Sig \\
\hline Intercept & 0.80 & 0.05 & 15.94 & $<2 \mathrm{e}-16$ & $* * *$ \\
\hline openness & 0.07 & 0.01 & 6.82 & $8.84 \mathrm{e}-12$ & $* * *$ \\
\hline richness & -0.09 & 0.01 & -8.12 & $4.49 \mathrm{e}-16$ & $* * *$ \\
\hline order & 0.13 & 0.01 & 11.82 & $2 \mathrm{e}-16$ & $* * *$ \\
\hline depth & 0.00 & 0.01 & 0.17 & 0.866 & \\
\hline
\end{tabular}

Note: '*' $\mathrm{p}<0.05$; ‘*’ $\mathrm{p}<0.01$; “***'p $<0.001$. 